\title{
Engineered Porous Materials for Mineral Dissolution Experiments
}

\author{
WILLIAM TAYLOR, ALEXIS NAVARRE-SITCHLER AND \\ BRIAN GORMAN
}

Colorado School of Mines

Presenting Author: williamtaylor@mymail.mines.edu

Physical heterogeneity in porous media has been shown to affect mineral dissolution rates due, in large part, to variability in fluid velocities and fluid residence times [1]. Natural systems are commonly characterized by physical heterogeneities such as hierarchical structures or variations in pore size, interconnectivity, and shape over a given domain [3]. The existence of these features in natural systems is thought to partially explain the several-order-of-magnitude discrepancies observed between lab and field derived dissolution rates [4]. While this difference is also thought to be a function of reactive surface area, length of weathering time, and intrinsic mineral surface factors, among others, physical heterogeneity in terms of pore complexity has not been well represented in lab scale experiments [3]. As such, this study seeks to better understand the relationship between pore architecture and mineral dissolution rates by varying physical heterogeneity as an experimental variable. To do so, traditional ceramic manufacturing methods will be used to produce anorthite cores with designed porosity for use in dissolution experiments.

To create porous anorthite cores, high purity precursor powders composed of $\mathrm{CaCO}_{3}, \mathrm{SiO}_{2}$, and $\mathrm{Al}_{2} \mathrm{O}_{3}$ are milled to $<10 \mu \mathrm{m}$ to increase reaction and densification driving forces [2]. This homogenized powder mixture is calcined for 48 hours at $1200^{\circ} \mathrm{C}$ in two steps. Pore formers, such as PMMA and/or carbon black, are then arranged in a temporary scaffold that is burned out during sintering leaving behind a pore network. These cores will then be used in dissolution experiments that will help elucidate the relationship between pore topology/complexity, fluid flow, and mineral dissolution rates.

[1] Jung \& Navarre-Sitchler (2018), Geochimica Et Cosmochimica Acta 234, 70-83.

[2] Kobayashi \& Kato (1994), Journal of the American Ceramic Society 77(3), 833-834.

[3] Li, Steefel \& Yang (2008), Geochimica Et Cosmochimica Acta 72(2), 360-377.

[4] White \& Brantley (2003), Chemical Geology 202(3-4), 479-506. 